\title{
Global birth prevalence and mortality from inborn errors of metabolism: a systematic analysis of the evidence
}

\author{
Donald Waters*, Davies Adeloye*, \\ Daisy Woolham, Elizabeth \\ Wastnedge, Smruti Patel, Igor \\ Rudan
}

Centre for Global Health Research, The Usher Institute for Population Health Sciences and Informatics, University of Edinburgh, Edinburgh Scotland, UK

*These authors contributed equally.

\section{Correspondence to:}

Professor Igor Rudan

Chair in International Health and Molecular Medicine

Joint Director, Centre for Global Health Research and WHO Collaborating Centre for Population Health Research and Training Director of Research, The Usher Institute for Population Health Sciences and Informatics The University of Edinburgh

MacKenzie House

30 West Richmond Street

Edinburgh EH8 9DX

Scotland, UK

Igor.Rudan@ed.ac.uk
Background Inborn errors of metabolism (IEM) are a group of over 500 heterogeneous disorders resulting from a defect in functioning of an intermediate metabolic pathway. Individually rare, their cumulative incidence is thought to be high, but it has not yet been estimated globally. Although outcomes can often be good if recognised early, IEM carry a high fatality rate if not diagnosed. As a result, IEM may contribute significantly to the burden of non-communicable childhood morbidity.

Methods We conducted a systematic literature review of birth prevalence and case fatality of IEM globally, with search dates set from 1980 to 2017. Using random-effects meta-analysis, we estimated birth prevalence of separate classes of IEM and all-cause IEM, split by geographical region. We also estimated levels of parental consanguinity in IEM cases and global case fatality rates and resultant child deaths from allcause IEM.

Findings 49 studies met our selection criteria. We estimate the global birth prevalence of all-cause IEM to be 50.9 per 100000 live births (95\% confidence intervals $(C I)=43.4-58.4$ ). Regional pooled birth prevalence rates showed the highest rates of IEM to be in the Eastern Mediterranean region (75.7 per 100000 live births, 95\% CI $=50.0$ 101.4), correlating with a higher observed rate of parental consanguinity in studies from this area. We estimate case fatality rates to be $33 \%$ or higher in low- and middle-income countries (LMICs), resulting in a minimum of 23529 deaths from IEM per year globally (95\% $\mathrm{CI}=20382-27427$ ), accounting for $0.4 \%$ of all child deaths worldwide.

Conclusions IEM represent a significant cause of global child morbidity and mortality, comprising a notable proportion of child deaths currently not delineated in global modelling efforts. Our data highlight the need for policy focus on enhanced laboratory capacity for screening and diagnosis, community interventions to tackle parental consanguinity, and increased awareness and knowledge regarding management of IEM, particularly in LMICs.

As outcomes improve in many areas of the world for common infectious causes of child morbidity and mortality, the contribution of other less common illnesses to the burden of disease in those under 5 years old is receiving increased attention $[1,2]$. One group of such diseases are the 'inborn errors of metabolism' (IEM), a heterogeneous group of over 500 disorders, individually rare but with a likely high cumulative incidence and potential to result in substantial mortality or long-term morbidity [3]. 
IEM are defined as monogenic diseases resulting in deficient activity of an individual enzyme, structural protein or transporter molecule in an intermediate metabolic pathway $[4,5]$. This deficiency can present clinically in a wide variety of ways, ranging from non-specific chronic issues such as childhood delay in attaining development milestones, to acute decompensation in the neonatal period with severe treatment-refractory metabolic acidosis or hypoglycaemia [2]. Most disorders are treatable if diagnosed early but can be rapidly fatal without prompt recognition [6]. Resulting from the heterogeneity in clinical presentation, which can overlap with many other diseases, diagnosis of IEM can prove difficult, and is often missed. Some IEM such as phenylketonuria (PKU) have been part of newborn screening tests in many countries for over 30 years, however rarer conditions are often not part of routine screening [4,6]. Diagnosis of these conditions often requires a high index of clinical suspicion combined with relatively novel sophisticated diagnostic investigations such as tandem mass spectrometry $[7,8]$. Diagnostic difficulty is more marked in low- and middle-income countries (LMICs) where access to advanced diagnostic approaches is limited due to resource constraints [9]. This is particularly of concern in areas with high levels of parental consanguinity, a known risk-factor for monogenic disorders such as IEM [7].

As of yet, there are no global estimates of the burden of morbidity or mortality associated with IEM, with IEM remaining part of the 'other' diseases section of estimates from the Interagency Group on Child Mortality Estimation (IGME), Maternal and Child Epidemiology Estimation (MCEE) or Global Burden of Disease (GBD) studies, and other similar large-scale global modelling efforts [1,10]. We are of the opinion that IEM likely contribute a significant proportion of this currently poorly understood subdivision of disease burden. For example, even based on an assumption that IEM incidence is as low as 1 in 10000 births globally, hypothetically, out of 140 million live births per year globally, 14000 children will be born with IEM. Given known high case fatality rates, particularly in LMICs due to limitations in diagnosis and management, IEM would result in a large number of under 5 deaths each year $[4,5]$. Without greater understanding of the contribution of IEM to the global disease burden, both as a whole and individually, the potential for advocacy of IEM as an important concern for policy makers and development of targeted screening and treatment approaches will remain severely limited. In an effort to combat this, we aimed in this study to provide global estimates of birth prevalence of IEM, and resultant mortality, in children under 5 years of age.

\section{METHODS}

\section{Search strategy}

A systematic search of published literature was performed on databases Medline, EMBASE and Global Health for the years 1980-2017 using the search terms shown in Appendix 1 in Online Supplementary Document. This was conducted in parallel by two separate reviewers to minimise risk of bias. Studies were evaluated using the selection criteria shown in Table 1 and case definition criteria.

\section{IEM case definitions}

Diagnoses of IEM have been based on varying newborn screening tests, including tandem mass spectrometry, gas chromatography, traditional enzyme assays, radiological investigations and/or clinical symp-

Table 1. Selection criteria for literature review

\begin{tabular}{l} 
Inclusion criteria: \\
Studies published 1980-2017 globally that referred to inborn errors of metabolism (IEM) among children \\
\hline Studies that directly attempted to estimate birth prevalence and/or under-5 mortality rate of all or specific classes of IEM \\
\hline Studies that provided information on determinants of IEM aetiology/occurrence, consanguinity rates, clinical features, management, case fatality \\
rates and/or outcomes \\
Exclusion criteria: \\
Studies that did not estimate the birth prevalence and/or under-five mortality of IEM \\
\hline Studies that were review articles, viewpoints and commentaries \\
\hline Studies that did not report total live births or relevant denominator from which birth prevalence and/or under-five mortality of IEM could be estimated \\
\hline Studies with ambiguous study design or analysis \\
\hline Studies without active follow-up periods \\
\hline Studies with unclear defined or inconsistently applied case definitions.
\end{tabular}


toms. To ensure relatively uniform approach to case definitions in this review, we checked that studies reported cases and deaths from all causes of IEM based on the International Classification of Diseases 10 ((ICD-10), ie, E70-E90) and Online Mendelian Inheritance in Man (OMIM). Eight IEM classes were identified from studies. Other classes of IEM returned too few data points and were not included in the meta-analysis (Table 2).

\section{Data extraction}

To minimise risk of bias, a parallel search (and double extraction) was conducted by two independent reviewers (DW and DA). Data were abstracted systematically on period of study, location, WHO region, study population, mean age or age range, number of IEM cases, birth prevalence rates, number of deaths, and case fatality rates (CFR) from IEM. For studies conducted on the same study site, population or cohort, the first chronologically published study was selected, and all additional data from additional studies were added in subsequently.

\section{Quality assessment}

Studies were assessed for quality using a modified Grading of Recommendations Assessment, Development and Evaluation (GRADE) framework [11]. Quality of studies was assessed under four criteria: i) study design - assesses adherence to standardized screening for determining IEM, and validating data before data entry; ii) sampling strategy - assesses if the sampling was representative of a larger population in the region of study; iii) statistical analysis - assesses the appropriateness of statistical and analytical methods in determining the outcome measure/s; and iv) study limitations - assesses explicit description of the study limitation with reference to each of the first three criteria (study design, sampling and analysis). Studies that were graded as high, moderate, low and very low quality, respectively (see Appendix 2 in Online Supplementary Document for details of grading). All 'very low' quality studies were excluded as were the majority of 'low' quality studies, some being included in quantitative analysis on the basis of well represented study designs.

\section{Data analysis}

A random effects meta-analysis (DerSimonian and Laird method) [12] was conducted on extracted crude birth prevalence rates for all and specific classes of IEM, and on reported numbers of IEM deaths and CFR. Standard errors were determined from the reported crude estimates and live births (or other relevant denominators when appropriate), assuming a binominal (or Poisson) distribution. Heterogeneity between studies was assessed using I-squared $\left(\mathrm{I}^{2}\right)$ statistics. Meta-estimates for birth prevalence rates were also split by WHO region. Birth prevalence and CFR meta-estimates were combined with United Nations Population Division (UNPD) data for the period 2015-2020 to estimate childhood deaths from IEM.

\section{RESULTS}

Our searches returned 25036 records. Following exclusion of duplicates and application of selection criteria, 49 studies were included in the final analysis. Search results are shown in Figure 1.

Table 2. Classes of inborn errors of metabolism (IEM) identified from studies

\begin{tabular}{ll} 
IEM cLASS & EXaMPIES \\
\hline Amino acid disorders & Phenylketonuria, homocystinuria \\
\hline Organic acid disorders & Propionic aciduria, methyl malonic aciduria, isovaleric aciduria, biotinidase deficiency \\
\hline Fatty acid disorders & Short or medium chain acyl-coenzyme A dehydrogenase deficiency (SCAD, MCAD) \\
\hline Lysosomal storage disorders & $\begin{array}{l}\text { Sphyngolipidoses (Fabry, Farber, Gauher and Niemann-Pick diseases), mucolipidoses, oligosaccharidoses } \\
\text { (fucosidosis, mannosidosis) }\end{array}$ \\
\hline Carbohydrate metabolism disorders & Galactosemia, Pompe's disease (glycogen); \\
\hline Urea cycle disorders & Citrullinemia, argininemia \\
\hline Mitochondrial disorders & Leigh syndrome \\
\hline Peroxisomal disorders & Zellweger syndrome, Refsum syndrome \\
\hline Others* & $\begin{array}{l}\text { Purine and pyrimidine disorders, metal disorders, porphyria and haematological disorders, lipid disorders and } \\
\text { myelin metabolism disorders }\end{array}$ \\
\hline
\end{tabular}

*Returned too few data points to be included in the meta-analysis. 


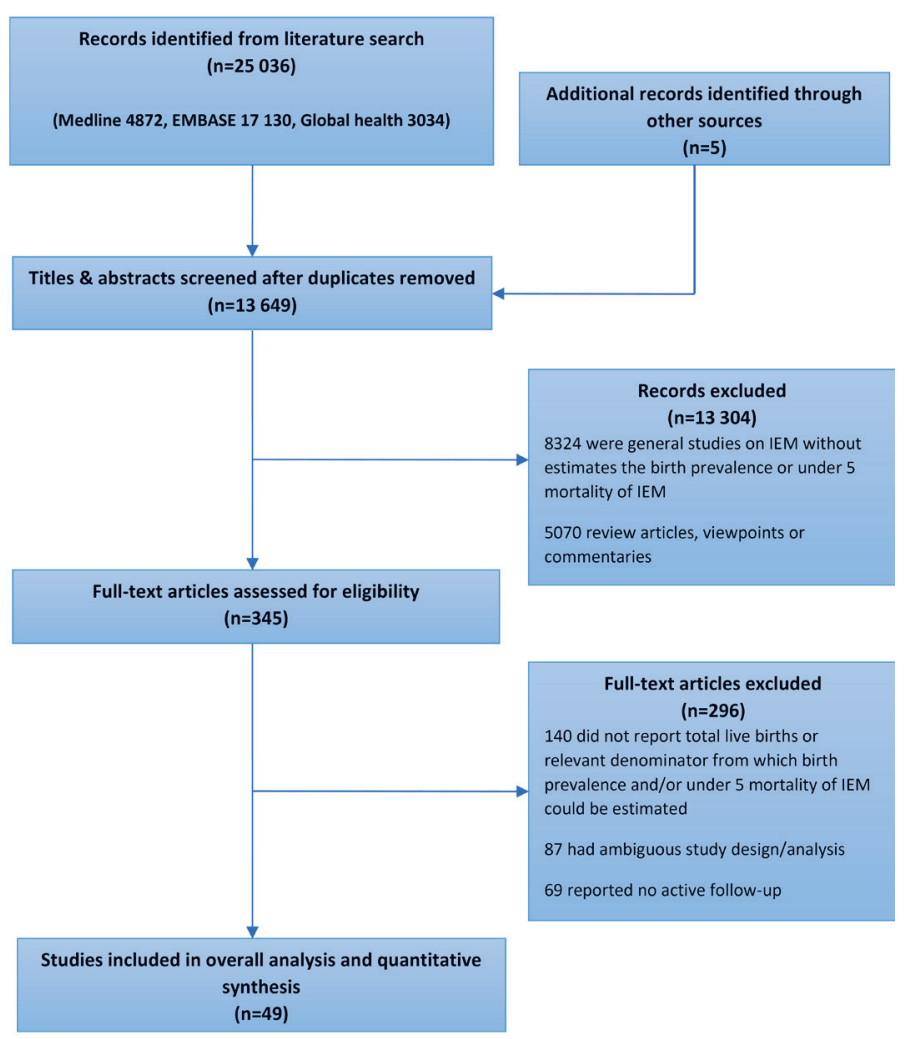

\section{Study characteristics}

Of the 49 studies included in the analysis, 33 reported estimates for all classes of IEM, with the remaining 16 studies only reporting for specific classes of IEM. The selected studies were from 38 countries globally. From the 33 studies that provided estimates for all classes of IEM, study period ranged from 2000 to 2014, with over 20 studies conducted after 2010. The majority of studies $(\mathrm{n}=13)$ were conducted in the WHO Western Pacific region (WPR A-5, WPR B-8). There were seven studies in each of European and Eastern Mediterranean regions, while the American and the South East Asian regions had four and two studies, respectively. There were no studies from sub-Saharan Africa. Table 3 shows study characteristics for studies reporting estimates for all classes of IEM, study characteristics of condition-specific studies are shown in Appendix 3 and 4 in Online Supplementary Document.

\section{Birth prevalence of IEM}

Figure 2 shows results for the meta-analysis of all IEM, with an overall birth prevalence estimate of 50.9 per 100000 live births (live births) (95\% confidence intervals 43.4-58.4 per 100000 LB).

Figure 1. PRISMA flowchart of literature search.

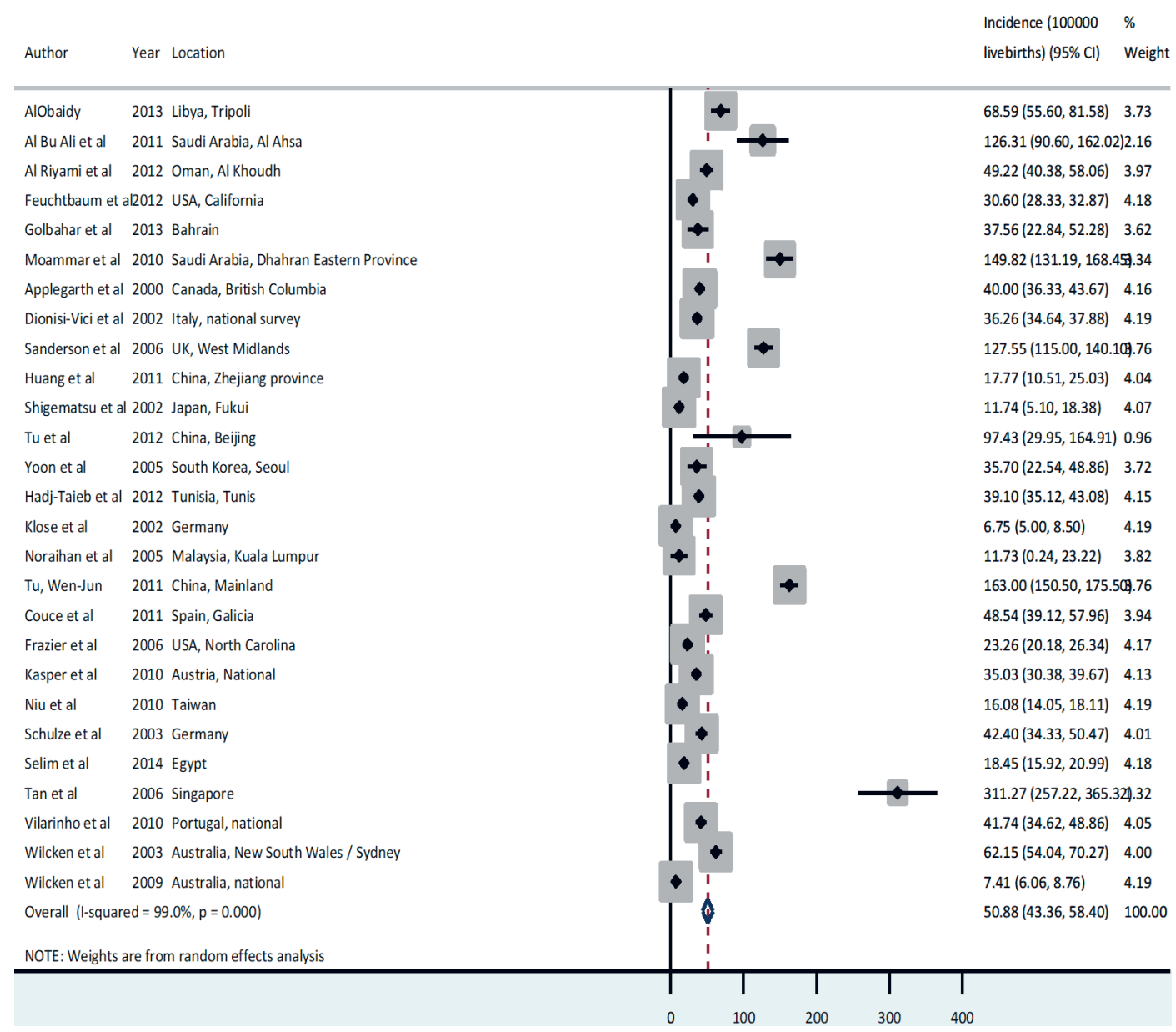

Figure 2. Birth prevalence of all inborn errors of metabolism (IEM). 


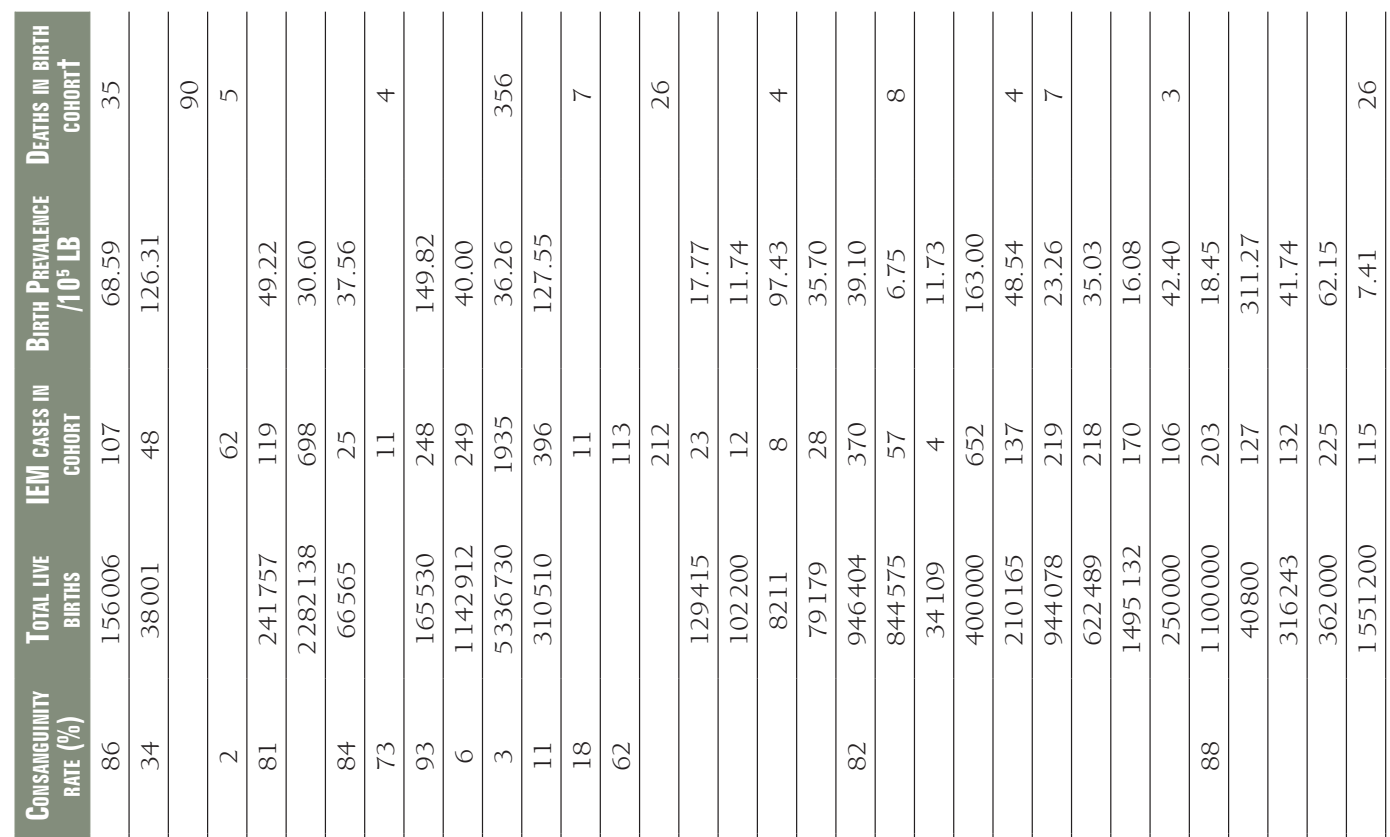

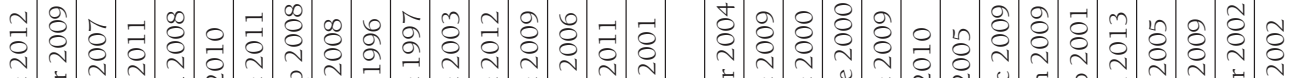
岗

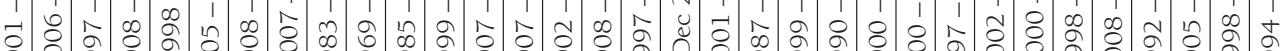

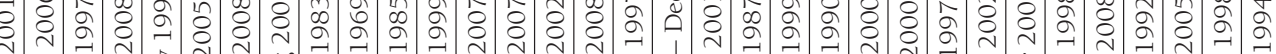
刍

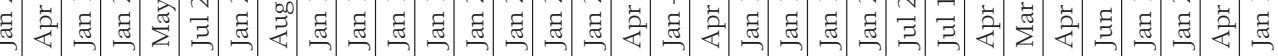
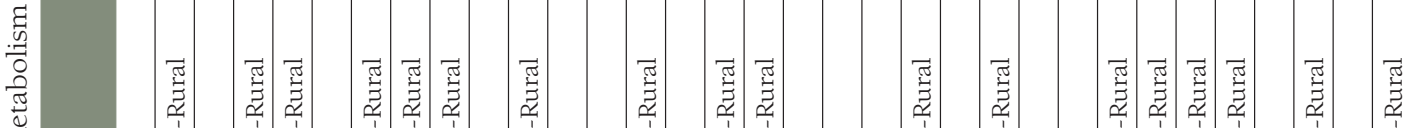
\begin{tabular}{l}
\hline \\
\hline
\end{tabular}

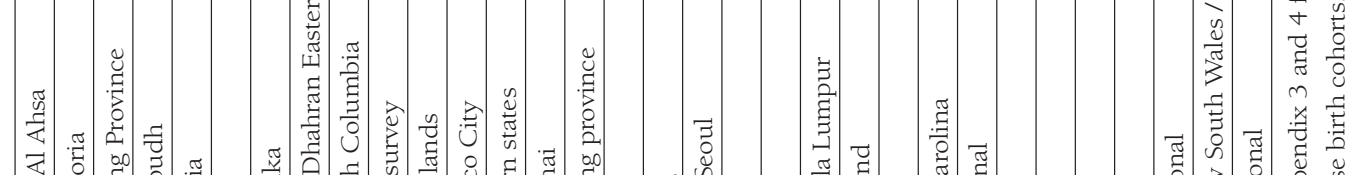

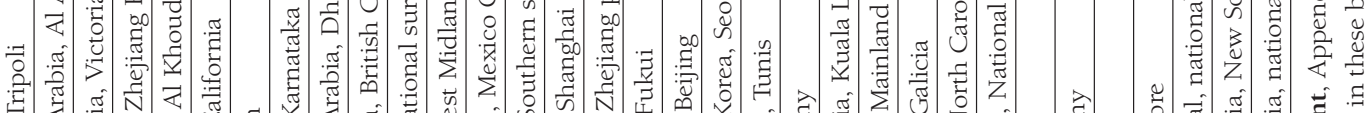

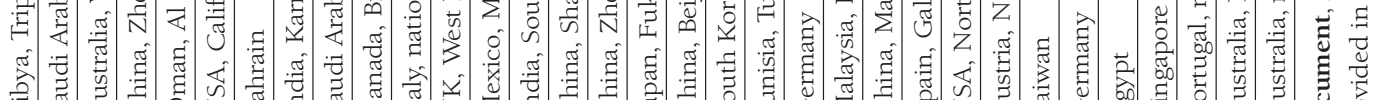
ज्ञ 
From the regional meta-estimates, EMR B and WPR $A$ had the highest birth prevalence rates of all-cause IEM at $75.7(95 \% \mathrm{CI}=50.0-101.4)$ and $73.1(95 \% \mathrm{CI}=39.7-106.5)$ per 100000 live births (LB) respectively (Figure 3, plates A-C).

Meta-estimates of individual classes of IEM showed amino acidurias to have the highest birth prevalence with 14.7 cases $(95 \% \mathrm{CI}=12.2-17.2)$ per $100000 \mathrm{LB}$, followed by lysosomal storage disorders with 13.3 (95\% CI $=9.48-17.02)$ per 10000 LB. Other IEM classes that reported high birth prevalence included organic acidurias, mitochondrial disorders, fatty acidurias and carbohydrate metabolism disorders with $8.7(95 \% \mathrm{CI}=7.2-10.3), 8.2(95 \% \mathrm{CI}=5.4-10.9), 6.5(95 \% \mathrm{CI}=5.2-7.9)$ and $6.2(95 \% \mathrm{CI}=4.5-7.9)$ cas-

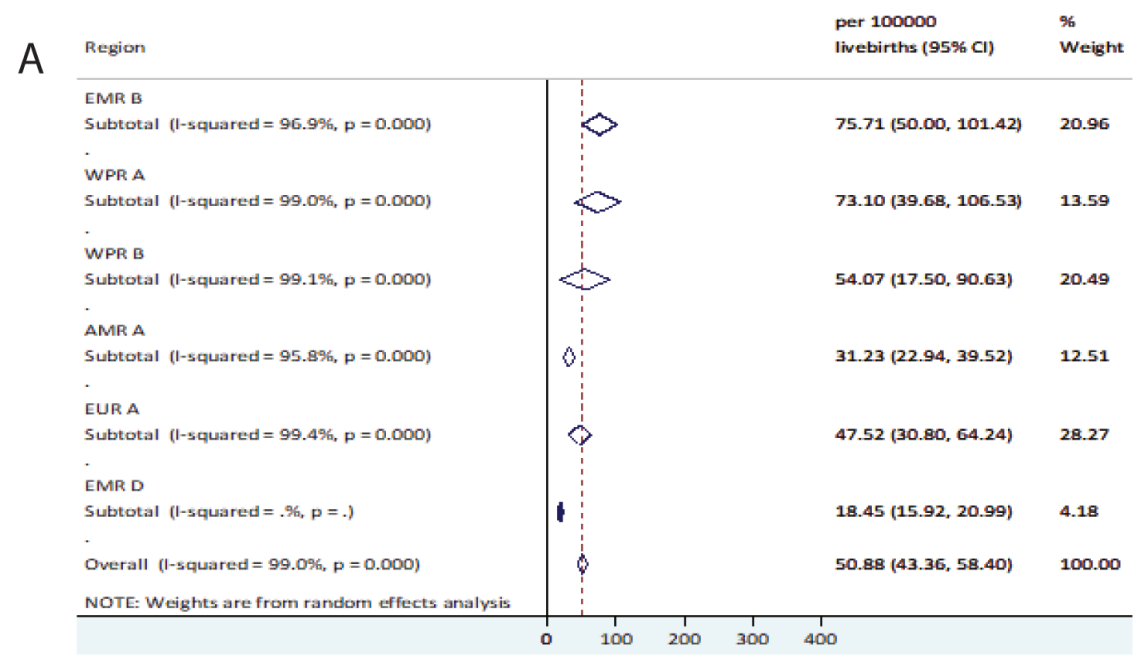

B

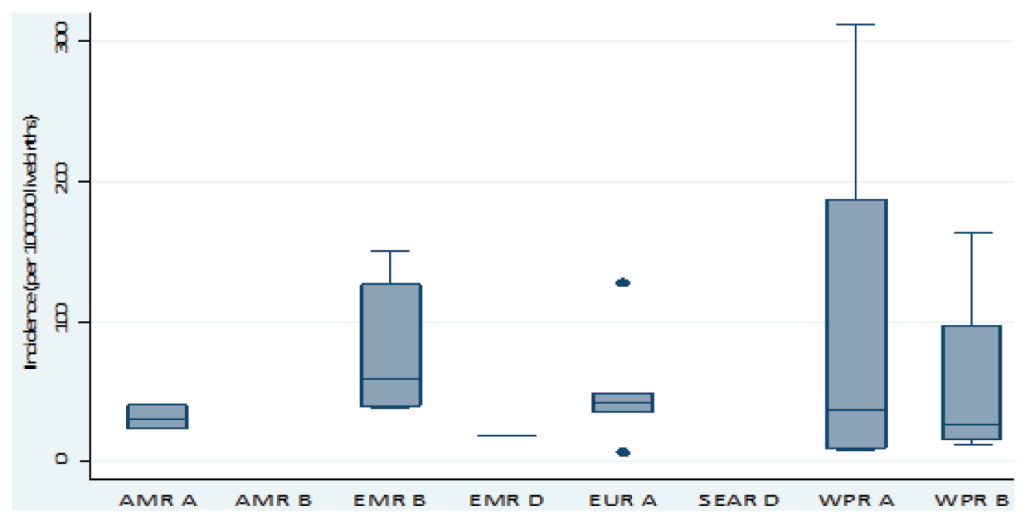

C

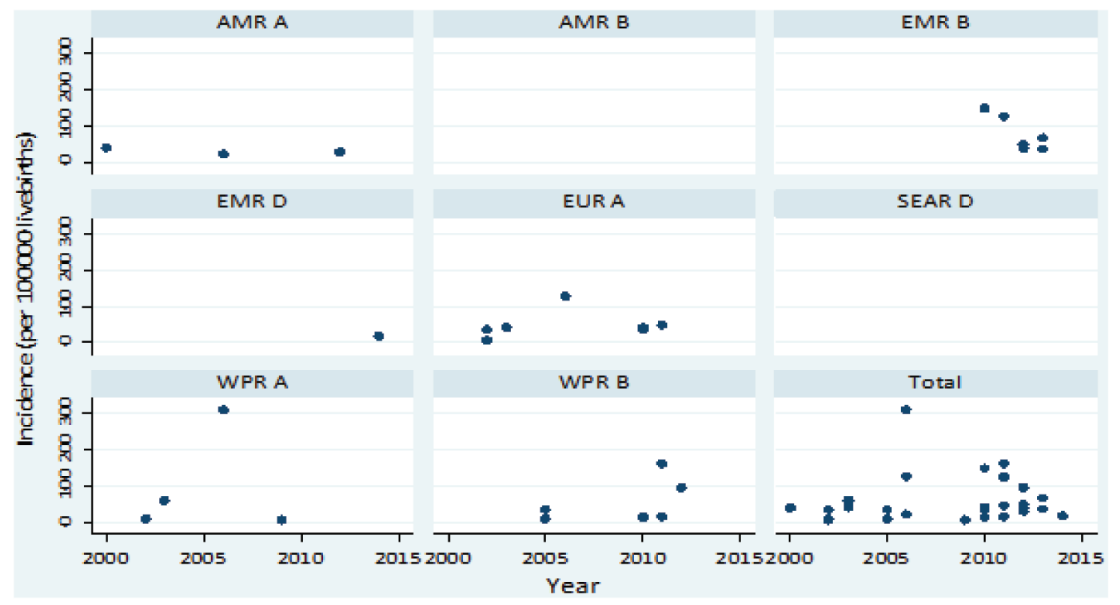

Figure 3. A. Regional meta-estimate of birth prevalence of all inborn errors of metabolism (IEM). B. Regional birth prevalence rates distribution of all IEM. C. Birth prevalence of IEM from all causes according to study region and period. 
es per 100000 LB, respectively. Some other notable IEM subclasses include phenylketonuria (a variant of amino aciduria) and medium chain acyl-coenzyme A dehydrogenase deficiency (a variant of fatty aciduria) with $6.6(95 \% \mathrm{CI}=5.3-7.8)$ and $5.8(95 \% \mathrm{CI}=4.4-7.2)$ per $100000 \mathrm{LB}$ respectively (45\% of total amino acidurias and $89 \%$ of total fatty acidurias respectively). When the crude estimates of the individual eight classes included in this review were pooled together (sensitivity analysis), we recorded a pooled estimate of 64.6 (95\% CI=48.5-81.1) cases per 100000 LB (Table 4 \& Appendix 3 in Online Supplementary Document).

\section{Parental consanguinity rates}

Few studies $(n=14)$ reported parental consanguinity rates among cases of IEM. The overall meta-estimate was 51.47 (95\% CI=30.20-72.73) percent (shown in Figure 4). From individual studies, Saudi

\begin{tabular}{|c|c|c|c|c|c|}
\hline Author & Year Location & & & Consanguinity (\%) (95 & 1) Weight \\
\hline Alobaidy & 2013 Libya, Tripoli & & $\rightarrow$ & $86.00(79.43,92.57)$ & 7.24 \\
\hline Al Bu Aliet al & 2011 Saudi Arabia, Al Ahsa & & & $34.00(20.60,47.40)$ & 7.08 \\
\hline Huang et al & 2012 China, Zhejiang Province & + & & $1.60(-1.52,4.72)$ & 7.28 \\
\hline Al Riyamiet al & 2012 Oman, A| Khoudh & & $\rightarrow$ & $81.00(73.95,88.05)$ & 7.23 \\
\hline Golbahar et al & 2013 Bahrain & & $\longrightarrow$ & $84.00(69.63,98.37)$ & 7.05 \\
\hline Kamate et al & 2010 India, Karnataka & & & $72.70(46.37,99.03)$ & 6.55 \\
\hline Moammar et a & 2010 Saudi Arabia, Dhahran Eastern Province & & $*$ & $92.80(89.58,96.02)$ & 7.28 \\
\hline Applegarth et a & I 2000 Canada, British Columbia & 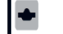 & & $6.00(3.05,8.95)$ & 7.28 \\
\hline Dionisi-Yiciet a & I 2002 Italy, national survey & 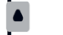 & & $3.00(2.24,3.76)$ & 7.29 \\
\hline Sanderson et a & 2006 UK, West Midlands & $\star$ & & $11.00(7.92,14.08)$ & 7.28 \\
\hline sabelet al & 2014 Mexico, Mexico city & & & $18.00(-4.70,40.70)$ & 6.73 \\
\hline Nigaraja et al & 2010 India, Southern states & & & $62.00(53.05,70.95)$ & 7.19 \\
\hline Hadj-Taieb et a & 2012 Tunisia, Tunis & & $\leftarrow$ & $81.20(77.22,85.18)$ & 7.27 \\
\hline Selimetal & 2014 Egypt & & $\neq$ & $88.00(83.53,92.47)$ & 7.26 \\
\hline Overall (1-squar & $\mathrm{red}=99.8 \%, \mathrm{p}=0.000)$ & & & $51.47(30.20,72.73)$ & 100.00 \\
\hline NOTE: Weights & are from random effects analysis & & & & \\
\hline
\end{tabular}

Figure 4. Meta-estimate of consanguinity rates of inborn errors of metabolism (IEM) from all causes.

Table 4. Birth prevalence of all and individual classes of inborn errors of metabolism (IEM) globally

\begin{tabular}{|c|c|c|c|c|}
\hline IEM & Class & $\begin{array}{l}\text { BIRTH PREVALENCE } \\
\text { (PER } 100000 \text { LB) }\end{array}$ & Confidence interval & Heterogeneity \\
\hline All IEM & All & 50.88 & $43.36-58.4$ & I-squared $=99.0 \%, P<0.001$ \\
\hline \multirow{4}{*}{ Amino acid disorders } & All & 14.69 & $12.20-17.17$ & I-squared $=97.8 \%, P<0.001$ \\
\hline & Phenylketonuria & 6.55 & $5.34-7.76$ & I-squared $=95.7 \%, P<0.001$ \\
\hline & Maple syrup urine disease & 1.22 & $0.82-1.61$ & I-squared $=87.3 \%, P<0.001$ \\
\hline & Homocystinuria & 0.41 & $0.20-0.63$ & I-squared $=81.7 \%, P<0.001$ \\
\hline \multirow{5}{*}{ Organic acid disorders } & All & 8.71 & $7.15-10.27$ & I-squared $=93.5 \%, P<0.001$ \\
\hline & Propionic aciduria & 1.07 & $0.73-1.42$ & I-squared $=90.5 \%, P<0.001$ \\
\hline & Methyl malonic aciduria & 1.68 & $1.19-2.16$ & I-squared $=89.3 \%, P<0.001$ \\
\hline & Isovaleric aciduria & 0.51 & $0.28-0.73$ & I-squared $=68.1 \%, P<0.001$ \\
\hline & Biotinidase deficiency & 1.64 & $1.02-2.26$ & I-squared $=90.5 \%, P<0.001$ \\
\hline \multirow{2}{*}{ Fatty acid disorders } & All & 6.51 & $5.14-7.89$ & I-squared $=96.2 \%, P<0.001$ \\
\hline & MCAD deficiency & 5.78 & $4.38-7.18$ & I-squared $=96.8 \%, P<0.001$ \\
\hline Lysosomal storage disorders & All & 13.25 & $9.48-17.02$ & I-squared $=98.6 \%, P<0.001$ \\
\hline Carbohydrate metabolism disorders & All & 6.19 & 4.45-7.94 & I-squared $=71.6 \%, P=0.002$ \\
\hline Urea cycle disorders & All & 2.91 & $1.90-3.92$ & I-squared $=83.7 \%, P<0.001$ \\
\hline Mitochondrial disorders & All & 8.16 & $5.42-10.91$ & I-squared $=92.2 \%, P<0.001$ \\
\hline Peroxisomal disorders & All & 4.13 & $2.78-5.48$ & I-squared $=95.4 \%, P<0.001$ \\
\hline
\end{tabular}

MCAD - medium chain acyl-coenzyme A dehydrogenase 
Arabia, Egypt, Libya, Bahrain, Tunisia and India had the highest consanguinity rates at $92 \%, 88 \%, 86 \%$, 84\%, $81 \%$ and $73 \%$ respectively. Lowest rates were recorded in China (1.6\%), Italy (3\%), Canada (6\%) and the United Kingdom (11\%).

\section{Deaths attributable to IEM}

Data on CFR were not available from the majority of studies, Table 5 shows data from studies that did describe CFR $(n=7)$. For all studies, data were reported with a denominator of life births and the length of follow-up of the birth cohort being studied was unclear, resultantly it was not possible to determine the age or age group at which deaths occurred.

Our overall meta-estimate of deaths attributable to IEM globally is $3.2(95 \% \mathrm{CI}=1.2-5.3)$ per 100000 LB, with a corresponding CFR of $13 \%(95 \% \mathrm{CI}=6 \% 21 \%)$ (Figure 5, panels A and B). AlObaidy et al reported in Libya a CFR over 30 times higher than Frazier et al in the USA (22.4 per 100000 LB compared with 0.7 per 100000 LB), likely in part due to differences in diagnosis, management and overall health care between and middle- and high-income settings [13,36].

\section{DISCUSSION}

\section{Main findings}

This study, as far as we are aware, provides the first global estimates of the birth prevalence and mortality from IEM among children under 5 years of age, in an effort to increase understanding of these potentially important causes of global child morbidity and mortality.

The estimated birth prevalence of all IEM globally was 50.9 (95\% CI=43.4-58.4) per 100000 LB. This falls within the confidence intervals of the pooled birth prevalence rates of the eight classes of IEM included in this review (shown in Table 4) of 64.6 cases per 100000 LB (95\% CI=48.5-81.1), adding confidence to our overall estimate (see also Appendix 3 in Online Supplementary Document). Our estimate of all IEM globally implies 500 IEM cases for every 1 million live births globally, suggesting 70587 (95\% $\mathrm{CI}=61$ 147-82 281) new cases of IEM per year, based on UNDP projections for live births in the period 2015-2020 [43]. This estimate may not be representative of all world regions, as it does not include data from all regions and income groups, or all possible IEM classes. In addition IEM are highly susceptible to underestimation due to missed diagnosis (a factor we were unable to account for). It is therefore likely our figure represents an under-estimate.

Regional pooled birth prevalence rates showed that EMR $B$ had the highest IEM birth prevalence rate of all-cause IEM at 75.7 (95\% CI=50.0-101.4) per 100000 . Although this could be a result of selection bias, it may also reflect this as an area with higher parental consanguinity rates which would be expected to report increased IEM birth prevalence $[7,44]$. Studies from the EMR B region showed the highest parental consanguinity rates in IEM cases of 34-93\% compared with the overall pooled consanguinity rate of $51.47 \%(95 \% \mathrm{CI}=30.20-72.73 \%)$.

The estimated global deaths attributable to all-cause IEM were $3.2(1.2-5.3)$ per 100000 LB, with a meta estimate of CFR of $13 \%$ (95\% CI=6-21\%). Again, these figures are likely to reflect an under-estimation as all but one study used for these estimates came from high-income countries, and none came from low-income countries. It should also be emphasised many early childhood deaths from IEM occur without an accurate diagnosis, particularly in LMICs [4,5]. Our data suggest a CFR of IEM in high-income settings ranging from $2-23 \%$, rising to $33 \%$ in middle-income countries, and possibly higher still in low-income countries (Table 5). Given that the vast majority of all IEM cases will occur in LMICs it may be appropriate to assume that 33\% represents a low bound of possible estimate for overall global CFR. This CFR applied to our estimated birth prevalence and combined with UNPD projections would suggest 23529 deaths per year from IEM (95\% CI=20382-27 427), approximating to $0.4 \%$ of all child deaths globally $[1,43]$.

\section{Limitations}

There are several important limitations to the conclusions of this study. Of the 49 studies selected for this review, only 33 studies provided estimate on all-cause IEM. These studies were focused in certain geographical areas, with no studies from low-income countries. The lack of studies from sub-Saharan Africa is of particular concern as this region has the highest number of under 5 deaths globally [1]. In addition, only seven studies were birth cohort studies (with reference denominators provided), limiting the 
A.

\begin{tabular}{|c|c|c|c|c|}
\hline Author. & Year Location & & Deaths/100000 LB 99 & Weight \\
\hline Alobaidy & 2013 Libya, Tripoli & & $22.40(14.97,29.83)$ & 5.17 \\
\hline Dionisi-Vici et & al 2002 Italy, national survey & $\bullet$ & $6.40(5.72,7.08)$ & 16.20 \\
\hline Klose et al & 2002 Germany & & $1.00(0.33,1.67)$ & 16.21 \\
\hline Couce et al & 2011 Spain, Galicia & & $1.90(0.04,3.76)$ & 14.50 \\
\hline Frazier et al & 2006 USA, North Carolina & & $0.70(0.17,1.23)$ & 16.31 \\
\hline Schulze et al & 2003 Germany & & $1.20(-0.16,2.56)$ & 15.37 \\
\hline Wilcken et al & 2009 Australia, national & & $1.70(1.05,2.35)$ & 16.23 \\
\hline Overall (1-squ & red $=97.3 \%, p=0.000)$ & 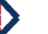 & $3.21(1.17,5.25)$ & 100.00 \\
\hline NOTE: Weight & are from random effects analysis & & & \\
\hline & 1 & & & \\
\hline
\end{tabular}

B.

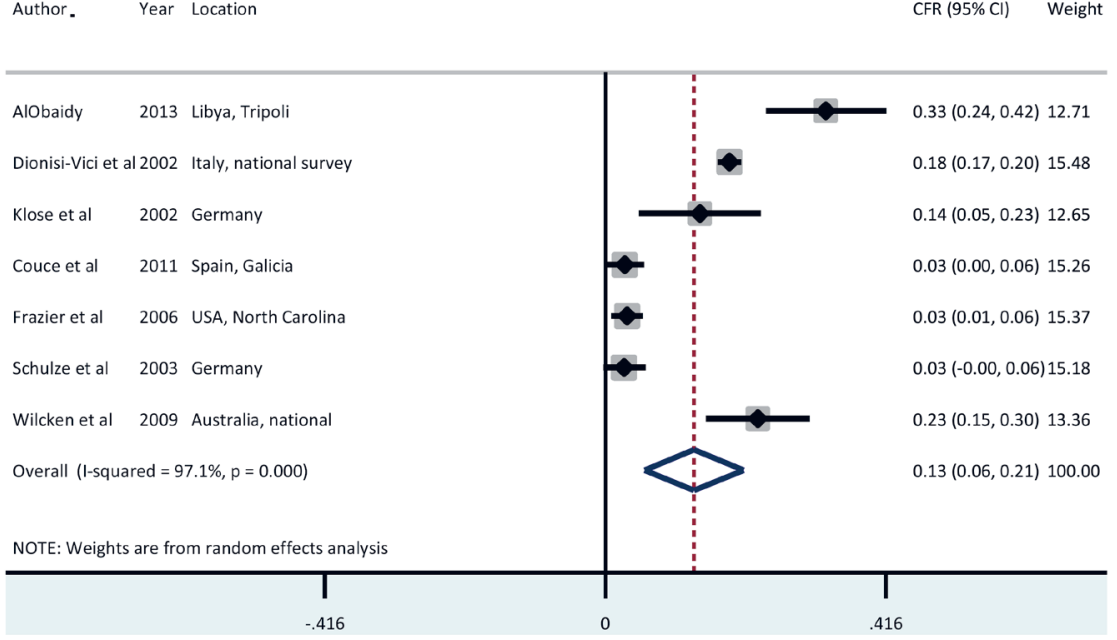

Figure 5. A. Meta-estimate of deaths attributable to inborn errors of metabolism (IEM) globally. B. Meta-estimate of case fatality rates from IEM globally.

Table 5. Deaths attributable to inborn errors of metabolism (IEM)

\begin{tabular}{|c|c|c|c|c|c|c|c|c|c|c|}
\hline Author & YeAR & Location & Setring & $\begin{array}{l}\text { \% CONSAN- } \\
\text { GUINITY }\end{array}$ & Total LB & $\begin{array}{l}\text { IEM } \\
\text { CASES }\end{array}$ & $\begin{array}{c}\text { BIRTH PREVI/ } \\
10^{5} \mathrm{LB}\end{array}$ & Deaths & $\begin{array}{c}\text { Deaths } / 10^{5} \\
\text { LB }\end{array}$ & $\begin{array}{c}\text { Case fatality } \\
\text { rate }(\%)\end{array}$ \\
\hline AlObaidy et al [13] & 2013 & Libya, Tripoli & Urban & 86 & 156006 & 107 & 68.6 & 33 & 22.4 & 32.7 \\
\hline Dionisi-Vici et al [23] & 2002 & Italy, national survey & Urban-Rural & 3 & 5336730 & 1935 & 36.3 & 356 & 6.4 & 18.4 \\
\hline Klose et al [32] & 2002 & Germany & Urban-Rural & N/A & 844575 & 57 & 6.8 & 8 & 1.0 & 14.0 \\
\hline Couce et al [35] & 2011 & Spain, Galicia & Urban & N/A & 210165 & 137 & 65.2 & 4 & 1.9 & 2.9 \\
\hline Frazier et al [36] & 2006 & USA, North Carolina & Urban & N/A & 944078 & 219 & 23.3 & 7 & 0.7 & 3.2 \\
\hline Schulze et al [8] & 2003 & Germany & Urban-Rural & N/A & 250000 & 106 & 42.4 & 3 & 1.2 & 2.8 \\
\hline Wilcken et al [42] & 2009 & Australia, national & Urban-Rural & N/A & 1551200 & 115 & 7.4 & 26 & 1.7 & 22.6 \\
\hline
\end{tabular}

N/A - not applicable, LB - live birth(s)

representativeness of our conclusions due to potential selection bias. It was unfortunate that no included studies reported clear follow-up periods, which could have allowed a more meaningful interpretation of mortality and CFR over the first five years of life. Additionally, some important studies that could have improved the quality of this review were conducted on children aged 0-14 years, without any breakdown of estimates by age, meaning that relevant estimates in 0-4 years could not be extracted. It is also import- 
ant to note that many studies were conducted in areas with high consanguinity rates, likely to result in a higher IEM prevalence than the overall global population $[7,44]$.

\section{Findings in context}

This study highlights the need for better understanding of IEM globally to facilitate improved diagnosis and management, particularly in sub-Saharan Africa where no data are currently available. Further largescale birth cohort studies are necessary to improve knowledge on the epidemiology of this important group of conditions.

Despite data limitations, our study has shown IEM represent an important cause of under 5 morbidity and mortality. Outcomes can be markedly improved by early recognition of IEM, and so a focus on increased clinician awareness globally and improved access to necessary investigations is essential to avoid missed diagnoses [2]. Newborn screening for common IEM has proved highly effective in many settings and it is important that capacity is built in LMIC health systems to foster similar screening programmes $[9,45]$. Laboratory capacity may be a significant limiting factor in screening and other investigations, particularly for novel and more complex metabolomic diagnostics, and we emphasise this as an important area to focus on with regards to health system strengthening $[3,6,45,46]$.

Our data also reinforces the fact that parental consanguinity plays an important role in the incidence of IEM, focused particularly in certain areas of the world $[7,44]$. Although often socioculturally complex, interventions to tackle this at a community level could play an important role in decreasing the number of births with IEM globally [47].

Treatment approaches for IEM are another essential area of focus. Emerging therapeutics including the use of molecular chaperones and substrate synthesis inhibitors show promising initial results, however due to high cost, are likely to be out of reach of many areas globally for the foreseeable future $[48,49]$. Despite this, the potential for extending existing management strategies employed in high-income settings to lower resourced populations has much potential to impact on global IEM morbidity and mortality [50]. In LMICs where access to paediatric endocrinology expertise is often limited or non-existent, even with an accurate diagnosis of an IEM, appropriate management can be difficult to provide [50,51]. The development and propagation of clear national and international protocols for managing IEM and associated metabolic crises could provide one avenue of improving the standard of care for this important patient group.

\section{CONCLUSIONS}

IEM represent an important cause of global child morbidity and mortality, comprising a significant proportion of child deaths which are as of yet poorly described in global modelling efforts. Although more population-level research is required to further establish the epidemiology of these conditions, our study emphasises several areas for current policy focus, including enhanced laboratory capacity for screening and diagnosis, community interventions to tackle parental consanguinity, and dissemination of knowledge regarding awareness and management of these important conditions.

\footnotetext{
Funding: This study was supported by the Maternal and Child Epidemiology Estimates (MCEE) grant from
the Bill and Melinda Gates Foundation and by The World Bank Group.
Authorship contributions: IR conceptualized and designed the study. DW and DA conducted the literature
searches and prepared the data. DA and IR conducted the analysis. DW, DA and IR wrote the manuscript. All
authors have critically reviewed and approved the final manuscript as submitted.
Declaration of interest: Igor Rudan is the Co-Editor in Chief of the Journal of Global Health. To ensure that any
possible conflict of interest relevant to the journal has been addressed, this article was reviewed according to
best practice guidelines of international editorial organizations. The authors completed the Unified Competing
Interest form at www.icmje.org/coi_disclosure.pdf (available on request from the corresponding author). The
authors declare no competing interests.
} 
1 Liu L, Oza S, Hogan D, Chu Y, Perin J, Zhu J, et al. Global, regional, and national causes of under-5 mortality in 200015: an updated systematic analysis with implications for the Sustainable Development Goals. Lancet. 2016;388:302735. Medline:27839855 doi:10.1016/S0140-6736(16)31593-8

2 Levy PA. Inborn Errors of Metabolism: Part 1: Overview. Pediatr Rev. 2009;30:131-7. Medline:19339386 doi:10.1542/ pir.30-4-131

3 Tebani A, Abily-Donval L, Afonso C, Marret S, Bekri S. Clinical metabolomics: the new metabolic window for inborn errors of metabolism investigations in the post-genomic era. Int J Mol Sci. 2016;17:E1167. Medline:27447622 doi:10.3390/ ijms17071167

4 Seymour CA, Thomason MJ, Chalmers RA, Addison GM, Bain MD, Cockburn F, et al. Newborn screening for inborn errors of metabolism: a systematic review. Health Technol Assess. 1997;1:i-iv, 1-95. Medline:9483156

5 Sanderson S, Green A, Preece MA, Burton H. The incidence of inherited metabolic disorders in the West Midlands, UK. Arch Dis Child. 2006;91:896-9. Medline:16690699 doi:10.1136/adc.2005.091637

6 Wilcken B, Wiley V, Hammond J, Carpenter K. Screening newborns for inborn errors of metabolism by tandem mass spectrometry. N Engl J Med. 2003;348:2304-12. Medline:12788994 doi:10.1056/NEJMoa025225

7 Rao AN, Kavitha J, Koch M, Kumar SV. Inborn errors of metabolism: review and data from a tertiary care center. Indian J Clin Biochem. 2009;24:215-22. Medline:23105838 doi:10.1007/s12291-009-0041-y

8 Schulze A, Lindner M, Kohlmuller D, Olgemoller K, Mayatepek E, Hoffmann GF. Expanded newborn screening for inborn errors of metabolism by electrospray ionization-tandem mass spectrometry: results, outcome, and implications. Pediatrics. 2003;111:1399-406. Medline:12777559 doi:10.1542/peds.111.6.1399

9 Jansen ME, Metternick-Jones SC, Lister KJ. International differences in the evaluation of conditions for newborn bloodspot screening: a review of scientific literature and policy documents. Eur J Hum Genet. 2016;25:10-6. Medline:27848945 doi:10.1038/ejhg.2016.126

10 GBD 2016 Causes of Death Collaborators. Global, regional, and national age-sex specific mortality for 264 causes of death, 1980-2016: a systematic analysis for the Global Burden of Disease Study 2016. Lancet. 2017;390:1151-210. Medline:28919116 doi:10.1016/S0140-6736(17)32152-9

11 Guyatt GH, Oxman AD, Vist GE. GRADE : an emerging consensus on rating quality of evidence and strength of recommendations. BMJ. 2008;336:924-6. Medline:18436948 doi:10.1136/bmj.39489.470347.AD

12 DerSimonian R, Laird N. Meta-analysis in clinical trials. Control Clin Trials. 1986;7:177-88. Medline:3802833 doi:10.1016/0197-2456(86)90046-2

13 AlObaidy H. Patterns of inborn errors of metabolism: A 12 year single-center hospital-based study in Libya. Qatar Med J. 2013;2013:57-65. Medline:25003067 doi:10.5339/qmj.2013.18

14 Al Bu Ali WH, Balaha MH, Al Moghannum MS, Hashim I. Risk factors and birth prevalence of birth defects and inborn errors of metabolism in Al Ahsa, Saudi Arabia. Pan Afr Med J. 2011;8:14. Medline:22121423 doi:10.4314/pamj.v8i1.71064

15 Goel H, Lusher A, Boneh A. Pediatric Mortality Due to Inborn Errors of Metabolism in Victoria, Australia: A Population-Based Study. JAMA. 2010;304:1070. Medline:20823432 doi:10.1001/jama.2010.1259

16 Huang X, Yang L, Tong F, Yang R, Zhao Z. Screening for inborn errors of metabolism in high-risk children: a 3-year pilot study in Zhejiang Province, China. BMC Pediatr. 2012;12:18. Medline:22364411 doi:10.1186/1471-2431-12-18

17 Al Riyami S, Al Maney M, Joshi SN, Bayoumi R. Detection of inborn errors of metabolism using tandem mass spectrometry among high-risk Omani patients. Oman Med J. 2012;27:482-5. Medline:23226820 doi:10.5001/omj.2012.115

18 Feuchtbaum L, Carter J, Dowray S, Currier RJ, Lorey F. Birth prevalence of disorders detectable through newborn screening by race/ethnicity. Genet Med. 2012;14:937-45. Medline:22766612 doi:10.1038/gim.2012.76

19 Golbahar J, Al-Jishi EA, Altayab DD, Carreon E, Bakhiet M, Alkhayyat H. Selective newborn screening of inborn errors of amino acids, organic acids and fatty acids metabolism in the Kingdom of Bahrain. Mol Genet Metab. 2013;110:98101. Medline:23916421 doi:10.1016/j.ymgme.2013.07.006

20 Kamate M, Chetal V, Kulgod V, Patil V, Christopher R. Profile of inborn errors of metabolism in a tertiary care centre PICU. Indian J Pediatr. 2010;77:57-60. doi:10.1007/s12098-010-0008-2. Medline:20135269

21 Moammar H, Cheriyan G, Mathew R, Al-Sannaa N. Incidence and patterns of inborn errors of metabolism in the Eastern Province of Saudi Arabia, 1983-2008. Ann Saudi Med. 2010;30:271. doi:10.4103/0256-4947.65254. Medline:20622343

22 Applegarth DA, Toone JR, Lowry RB. Incidence of inborn errors of metabolism in British Columbia, 1969-1996. Pediatrics. 2000;105:e10. Medline:10617747 doi:10.1542/peds.105.1.e10

23 Dionisi-Vici C, Rizzo C, Burlina AB, Caruso U, Sabetta G, Uziel G, et al. Inborn errors of metabolism in the Italian pediatric population: a national retrospective survey. J Pediatr. 2002;140:321-7. Medline:11953730 doi:10.1067/ mpd.2002.122394

24 Ibarra-González I, Fernández-Lainez C, Reyes-González D, Belmont-Martínez L, Guillén-López S, Monroy-Santoyo $S$, et al. Inborn errors of intermediary metabolism in critically ill Mexican newborns. J Inborn Errors Metab Screen. 2014;2:232640981452964. doi:10.1177/2326409814529649

25 Nagaraja D, Mamatha SN, De T, Christopher R. Screening for inborn errors of metabolism using automated electrospray tandem mass spectrometry: Study in high-risk Indian population. Clin Biochem. 2010;43:581-8. Medline:20026021 doi:10.1016/j.clinbiochem.2009.12.009

26 Han LS, Ye J, Qiu WJ, Gao XL, Wang Y, Gu XF. Selective screening for inborn errors of metabolism on clinical patients using tandem mass spectrometry in China: A four-year report. J Inherit Metab Dis. 2007;30:507-14. Medline:17347912 doi:10.1007/s10545-007-0543-9

27 Huang XW, Yang J, Tong F, Yang R, Mao H, Zhou X, et al. Screening for neonatal inborn errors of metabolism by electrospray ionization-tandem mass spectrometry and follow-up. Zhonghua Er Ke Za Zhi. 2011;49:765-70. Medline:22321184 
28 Shigematsu Y, Hirano S, Hata I, Tanaka Y, Sudo M, Sakura N, et al. Newborn mass screening and selective screening using electrospray tandem mass spectrometry in Japan. J Chromatogr B Analyt Technol Biomed Life Sci. 2002;776:39-48. Medline:12127323 doi:10.1016/S1570-0232(02)00077-6

$29 \mathrm{Tu}$ W, He J, Dai F, Wang X, Li Y. Impact of inborn errors of metabolism on admission in a neonatal intensive care unit - a prospective cohort study. Indian J Pediatr. 2012;79:494-500. Medline:21660401 doi:10.1007/s12098-011-0464-3

30 Yoon H-R, Lee KR, Kang S, Lee DH, Yoo H-W, Min W-K, et al. Screening of newborns and high-risk group of children for inborn metabolic disorders using tandem mass spectrometry in South Korea: a three-year report. Clin Chim Acta. 2005;354:167-80. Medline:15748614 doi:10.1016/j.cccn.2004.11.032

31 Hadj-Taieb S, Nasrallah F, Hammami MB, Elasmi M, Sanhaji H, Moncef F, et al. Aminoacidopathies and organic acidurias in Tunisia: a retrospective survey over 23 years. Tunis Med. 2012;90:258-61. Medline:22481200

32 Klose DA, Kolker S, Heinrich B, Prietsch V, Mayatepek E, von Kries R, et al. Incidence and short-term outcome of children with symptomatic presentation of organic acid and fatty acid oxidation disorders in Germany. Pediatrics. 2002;110:120411. Medline:12456920 doi:10.1542/peds.110.6.1204

33 Noraihan MN, See MH, Raja R, Baskaran TP, Symonds EM. Audit of birth defects in 34,109 deliveries in a tertiary referral center. Med J Malaysia. 2005;60:460-8. Medline:16570708

34 Tu W-J. Methylmalonic Acidemia in Mainland China. Ann Nutr Metab. 2011;58:281-281. Medline:21912104 doi:10.1159/000331469

35 Couce ML, Sanchez-Pintos P, Diogo L, Leao-Teles E, Martins E, Santos H, et al. Newborn screening for medium-chain acyl-CoA dehydrogenase deficiency: regional experience and high incidence of carnitine deficiency. Orphanet J Rare Dis. 2013;8:102. Medline:23842438 doi:10.1186/1750-1172-8-102

36 Frazier DM, Millington DS, McCandless SE, Koeberl DD, Weavil SD, Chaing SH, et al. The tandem mass spectrometry newborn screening experience in North Carolina: 1997-2005. J Inherit Metab Dis. 2006;29:76-85. Medline:16601872 doi:10.1007/s10545-006-0228-9

37 Kasper DC, Ratschmann R, Metz TF, Mechtler TP, Möslinger D, Konstantopoulou V, et al. The National Austrian Newborn Screening Program - Eight years experience with mass spectrometry. Past, present, and future goals. Wien Klin Wochenschr. 2010;122:607-13. Medline:20938748 doi:10.1007/s00508-010-1457-3

38 Niu DM, Chien YH, Chiang CC, Ho HC, Hwu WL, Kao SM, et al. Nationwide survey of extended newborn screening by tandem mass spectrometry in Taiwan. J Inherit Metab Dis. 2010;33:S295-305. Medline:20567911 doi:10.1007/ s10545-010-9129-z

39 Selim LA, Hassan SAH, Salem F, Orabi A, Hassan FA, El-Mougy F, et al. Selective screening for inborn errors of metabolism by tandem mass spectrometry in Egyptian children: A 5year report. Clin Biochem. 2014;47:823-8. Medline:24731791 doi:10.1016/j.clinbiochem.2014.04.002

40 Tan IK, Gajra B, Lim MS. Study of inherited metabolic disorders in Singapore - 13 years experience. Ann Acad Med Singapore. 2006;35:804-13. Medline:17160197

41 Vilarinho L, Rocha H, Sousa C, Marcao A, Fonseca H, Bogas M, et al. Four years of expanded newborn screening in Portugal with tandem mass spectrometry. J Inherit Metab Dis. 2010;33 Suppl 3:S133-8. Medline:20177789 doi:10.1007/ s10545-010-9048-z

42 Wilcken B, Haas M, Joy P, Wiley V, Bowling F, Carpenter K, et al. Expanded newborn screening: outcome in screened and unscreened patients at age 6 years. Pediatrics. 2009;124:e241-8. Medline:19620191 doi:10.1542/peds.2008-0586

43 United Nations. World Population Prospects 2017 Revision 2017.

44 Bittles AH, Black ML. Consanguinity, human evolution, and complex diseases. Proc Natl Acad Sci U S A. 2010;107:177986. Medline:19805052 doi:10.1073/pnas.0906079106

45 Pourfarzam M, Zadhoush F. Newborn Screening for inherited metabolic disorders; news and views. J Res Med Sci. 2013;18:801-8.

46 Schulze A, Lindner M, Kohlmüller D, Olgemöller K, Mayatepek E, Hoffmann GF. Expanded newborn screening for inborn errors of metabolism by electrospray ionization-tandem mass spectrometry: results, outcome, and implications. vol. 111. 2003.

47 Darr A, Small N, Ahmad WIU, Atkin K, Corry P, Modell B. Addressing key issues in the consanguinity-related risk of autosomal recessive disorders in consanguineous communities: lessons from a qualitative study of British Pakistanis. J Community Genet. 2016;7:65-79. Medline:26363620 doi:10.1007/s12687-015-0252-2

48 Schwartz IV, de Souza CFM, Giugliani R. Treatment of inborn errors of metabolism. J Pediatr (Rio J). 2008;84:S8-19. Medline:18758655 doi:10.1590/S0021-75572008000500003

49 Muntau AC, Leandro J, Staudigl M, Mayer F, Gersting SW. Innovative strategies to treat protein misfolding in inborn errors of metabolism: pharmacological chaperones and proteostasis regulators. J Inherit Metab Dis. 2014;37:505-23. Medline:24687294 doi:10.1007/s10545-014-9701-z

50 Afroze B, Lakhani L, Naz F, Somani S, Yunus ZM, Brown N. Challenges identified in the management of patients with inherited metabolic disorders - A five year experience from Pakistan. Egypt J Med Hum Genet. 2016;17:259-64. doi:10.1016/j.ejmhg.2016.03.002

51 Das SK. Inborn Errors of Metabolism: Challenges and Management. Indian J Clin Biochem. 2013;28:311-3. Medline:24426231 doi:10.1007/s12291-013-0371-7 